\title{
É POSSÍVEL FALAR DE GESTÃo DE CARREIRA NO BRASIL?
}

\author{
Por Maria José Tonelli \\ Professora da FGV-EAESP \\ E-mail: maria.jose.tonelli@fgv.br
}

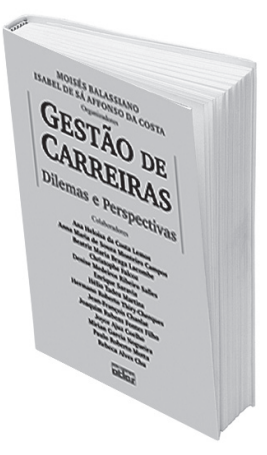

GESTÃO DE CARREIRAS: DILEMAS E PERSPECTIVAS

De Moisés Balassiano e Isabel de Sá Affonso da Costa (Orgs.)

Editora Atlas, São Paulo, 2006, 221p.

Moisés Balassiano e Isabel de Sá Afonso da Costa são os organizadores desta apropriada coletânea sobre o tema de carreiras em nosso país. O livro reúne artigos teóricos e pesquisas empíricas de vários pesquisadores brasileiros e apresenta também um texto de pesquisadores estrangeiros ligados a instituições francesas de ensino e pesquisa, Christophe Falcoz e JeanFrançois Chanlat.

Em boa hora, o livro de Balassiano e Costa propõe a discussão do tema da carreira sem fugir às contradições inevitáveis que a questão traz no momento atual. O tema é tratado por diferentes prismas, que problematizam os dilemas de uma individualidade mutante em face das profundas transformações das sociedades contemporâneas. Na apresentação do livro,
Maria Tereza Gomes, redatora-chefe da revista Você S/A, mostra que estamos em uma encruzilhada, pois, se o individualismo extremo prevalecer, não haverá mais o sentido de coletivo, fundamental para o crescimento e desenvolvimento das corporações.

Apesar de se tratar de uma coletânea, o livro apresenta uma unidade. Após a Introdução, em que os organizadores apresentam o projeto coletivo do livro, são apresentados 11 artigos, que destacaremos brevemente a seguir.

O artigo de Paulo Roberto Motta, que abre a coletânea, apresenta uma visão geral do contexto que, há mais de 50 anos, incentivou a carreira gerencial, mostrando que hoje esses valores mudaram: de um lado, o individualismo está mais presente; de ou- tro, as empresas estão mais próximas da comunidade. Para que o indivíduo possa conduzir sua própria carreira, é necessário desenvolver competências e empregabilidade. Contudo, o autor mostra a existência de contradições nesse processo, pois ao mesmo tempo em que a individualidade é encorajada, há também pressões no sentido da conformidade e da obediência para a obtenção de recompensas ou bônus financeiros.

Em seu artigo, Thiry-Cherques discute, a partir de evidências de um estudo empírico, o sentido de individualismo nas empresas brasileiras. Seu estudo foi realizado com 85 executivos das regiões norte e sudeste do país. $\mathrm{O}$ autor observa que o tipo de individualismo definido por ele de "possessivo" está fortemente presente no gru- 
po pesquisado. Para Thiry-Cherques, esse individualismo implica comportamentos de autonomia, mas também de sujeição aos esquemas regulatórios das empresas.

O próximo artigo, de Ana Heloisa da Costa Lemos, analisa o conceito controverso de empregabilidade. A autora recorre a pesquisadores contemporâneos importantes, como Zarifian e Hirata, para defender que o conceito de empregabilidade revela o deslocamento do conceito de competência em decorrência de mudanças mais profundas no sistema econômico. Buscando referências também em autores nacionais, Lemos faz uma crítica contundente das implicações que a palavra produz, e mostra a crescente individualização do emprego e do desemprego no Brasil.

O artigo escrito por Isabel de Sá Affonso da Costa e Anna Maria de Souza Monteiro Campos discute que a carreira teve um papel central no contrato psicológico que se estabelecia entre as pessoas e a organização. Se, de um lado, a identidade das pessoas foi construída em torno do projeto de trabalho, que teve - e continua a ter centralidade na construção de si, por outro, os frágeis e efêmeros vínculos contemporâneos levam ao que as autoras chamaram de "abertura ao acaso".

A carreira proteana é discutida no artigo de Helio Tadeu Martins. Nele,o autor apresenta os principais tipos de carreira e relaciona o conceito com práticas de gestão de pessoas, a partir da análise de sete universidades corporativas brasileiras. As conclusões do autor mostram que muitas práticas gerencias corporativas baseiam o gerenciamento da carreira nas ações da área de Recursos Humanos, e não no seu auto-gerenciamento.

Joyce Ajuz Coelho mostra em seu artigo os caminhos que levaram à emergência do modelo de carreira sem fronteiras, em contraposição ao sentido tradicional de carreira. De acordo com a autora, a carreira sem fronteira é o modelo paradigmático dos novos tempos.

Extremamente pertinente para os que estão no mundo do ensino da Administração, o artigo de Beatriz Maria Braga Lacome e Rebeca Chu trata da carreira do professor universitário. As autoras realizaram entrevistas com 19 professores e, a partir delas, observam que, entre eles, há uma forte vinculação com o trabalho, autonomia para o desenvolvimento de competências, a existência de uma rede de relacionamentos e mobilidade profissional todas características do conceito de carreira sem fronteiras, "que sugere a independência e autonomia de carreira em relação a uma única organização" (p. 109).

Denise Medeiros Ribeiro Salles e Miriam Garcia Nogueira discutem a questão da carreira no setor público. De acordo com elas, esse setor está hoje defasado dos benefícios permitidos pelas novas tecnologias, e, desde o princípio, os planos de carreira baseiam-se na noção de cargos. A Constituição de 1988 impede que ocupantes de cargos efetivos possam ascender funcionalmente, já que o processo de admissão nesses cargos está vinculado exclusivamente aos concursos públicos. Além da discussão sobre a inflexibilidade presente nesse tipo de carreira, o artigo traz um belo resgate histórico dos diferentes momentos da administração das pessoas nesse setor.

Também sobre o setor público, o artigo de Enrique Saravia traz relevante contribuição sobre o tema dentro da reforma do Estado e da Administração Pública, com críticas ao tipo ideal weberiano que tornou o sistema mais rígido. A noção de função publica, o conceito de funcionário público e os sistemas de emprego público são apre- sentados nesse artigo, com comparações interessantes com os sistemas de outros países.

Os dois últimos artigos discutem a carreira após os 40 anos. Joaquim Rubens Fontes Filho mostra que, no processo de renovação das empresas, tanto no exterior como em nosso país, os executivos com mais de 40 foram substituídos por jovens com salários mais baixos. O autor questiona a aplicabilidade do conceito de carreira sem fronteiras no mercado de trabalho brasileiro. $\mathrm{O}$ autor apresenta dados da força de trabalho no Brasil e problematiza o impacto do amadurecimento da força de trabalho para as organizações.

Nessa mesma direção, Falcoz e Chanlat mostram que a possibilidade de a carreira ficar estagnada está associada a diversos fatores. Em geral, de acordo com os autores, quanto mais avançada a idade, maior a chance de estagnação. O estudo empírico conduzido com 58 profissionais mostra que fatores organizacionais e individuais também interferem nas perspectivas de continuidade de trabalho, como, por exemplo, o tempo de permanência nos cargos, a concorrência no setor, as políticas de aposentadoria e os sentimentos envolvidos na aposentadoria.

É possível falar de gestão de carreiras no Brasil? Os autores mostram que sim, apesar das dificuldades inevitáveis que o tema enfrenta por aqui. Em síntese, o livro apresenta uma visão abrangente sobre a questão de carreiras no Brasil. Desse modo, a leitura dessa coletânea é extremamente relevante para pesquisadores, professores de Administração e profissionais da área de Gestão de Pessoas. Mas consideramos que se trata de uma leitura adequada também para o público executivo, que muito tem a se beneficiar, pessoal e profissionalmente, de todos os aspectos aqui tratados. 